\title{
Histological assessment of effect of Cinnamomum Zeylanicum Extract on Experimentally Induced Cutaneous Wound Healing in Rats \\ Hala Khalil Ahmed (BSC) ${ }^{1}$ and Ban A Ghani (BDS, MSc ,PhD) ${ }^{2}$
}

Abstract

Background: A wound may be defined as a disruption of the integrity and role of the tissues in the body. Healing process, which is a normal biological event in the body, is done by many precise, strict and highly programmed phases, the four phases of healing include: hemostasis, inflammation, proliferation, and repair. The herbal medicine is a branch of the complementary and alternative medicine. Cinnamon is a spice that is made from the inner bark of trees has antioxidant and anti-inflammatory properties.

Objective: Histological assessment of effect of Cinnamomum Zeylanicum Extract on Experimentally Induced Cutaneous Wound Healing in Rats.

Patients and Methods: Eighteen male albino rats (Rattus norvegicus albinus)of about 250$350 \mathrm{gm}$, were used in this study. Two circular full-thickness wounds were made on the dorsum region of each animal with a sterile biopsy punch(5mm diameter).Local cinnamomum zeylanicum essential oil application was done on wounds of the left side as experimental group, whereas the right side was left to heal spontaneously as control. The healing process was followed for the periods (1,3 and 7days), and specimens were prepared for histological analysis.

Results: Histological examination showed wound contraction highest mean values for control group at day 1 and decreased with time and highest mean values of inflammatory cells parameter and blood vessel counts were recorded in experimental groups at days 1 and 3 ,while epithelial thickness showed increased values with time in all groups.

Conclusion: The study revealed that local application of cinnamomum zeylanicum was effective in promoting wound healing process.

Keywords: Wound healing, cinnamomum zeylanicum, rats.

Corresponding Author: dr.ban61@yahoo.com

Received: $9^{\text {th }}$ June 2019

Accepted: $16^{\text {th }}$ June 2019

DOI:https://doi.org/10.26505/DJM.18024710609

\footnotetext{
${ }^{1}$ College of Dentistry -Babylon University- Babylon- Iraq

${ }^{2}$ Collage of Dentistry - University of Baghdad- Baghdad -Iraq.
}

\section{Introduction}

Cutaneous healing mechanism is an physiological process consisting of essential and highly programmed aggression of several cell type and their end 
Histological assessment of effect of Cinnamomum Zeylanicum Extract on Experimentally Induced

Cutaneous Wound Healing in Rats

products [1]. Lead to restore the wound induced by a local collaboration begin first in the inflammatory stage. Depending on the cell strains compromised by the injury several factors can interact with one or several phases of this process, thus result in impaired healing process [2]. Herb Cinnamomum zeylanicum (CZ)(mostly named by cinnamon) has a good and long history of a spice and flavoring agents. Two kind of cinnamon present : common cinnamon named by "ceylon cinnamon" or (Cinnamomum zeylanicum) and cassia cinnamon (Cinnamomum aromaticum) which is called as "Chinese cinnamon" [3]. Cinnamon exhibits many biological functions include: anti-inflammatory [4], antioxidant $[5,6]$ and anti-microbial $[6,7]$.

\section{Patients and Methods}

\section{Experimental design}

The study was ethically approved by Committee of College of

Dentistry/University of Baghdad. Eighteen Albino rats have a body weight of (250$350 \mathrm{gm})$ and age of (1-2) months were taken in the study [3]. All rats were remain under good ventilation conditions, temperature, feeding and housing, and eat a standard diet (pellet) with a tap water of an easy access.

The Animals were putted in standard special cages and remain 1 week in the same environment, and remain fasted before the operation for about 6-7 hours. The animals randomly divided into three main groups
(6 rats in each) according to the healing intervals (1,3 and 7days).Two full thickness circular punch biopsy were made on the dorsum of each rat with sterile $5 \mathrm{~mm}$ punch biopsy instrument [8].the wound at right side was left to heal spontaneously as control. Whereas the left side treated daily with $\mathrm{CZ}$ essential oil.

\section{Surgical procedures}

Every animal was weighed in order to determine the dose of anesthesia required .The animal was placed on surgical table and general anesthesia was done by xylazine $2 \%$ (0.4 mg/kg B.W.)and ketamine HCL 50mg (40 mg/kg-B.W.) intra muscular injection. Removal of skin hair of the dorsal region was done first by hair clipper then by hair removal lotion. The skin was swept with $70 \%$ ethyl alcohol for the purpose of disinfection. Two full thickness skin wounds of circular area $2 \mathrm{~mm}$ depth [9] were made on dorsal skin Figure (1), distant $2.5 \mathrm{~cm}$ from one other, by a biopsy punch of $5 \mathrm{~mm}$ diameter. The two wounds were identified as right(control) was irrigated with distilled water and left (experimental) locally treated with $\mathrm{CZ}$ oil $(10 \mu \mathrm{l})$ by micropipette Figure (2). At the end of each healing period $(1,3$, and 7days) each rat was given anesthesia. The wound was lined including about $5 \mathrm{~mm}$ of the surrounding normal tissue and a full thickness skin was excised by surgical blade. The specimens were put in a plastic biopsy container filled with $10 \%$ formaldehyde for fixation. 


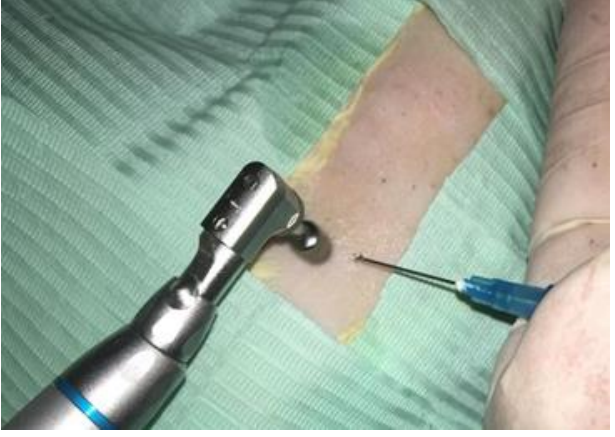

Figure (1): Punching with irrigation

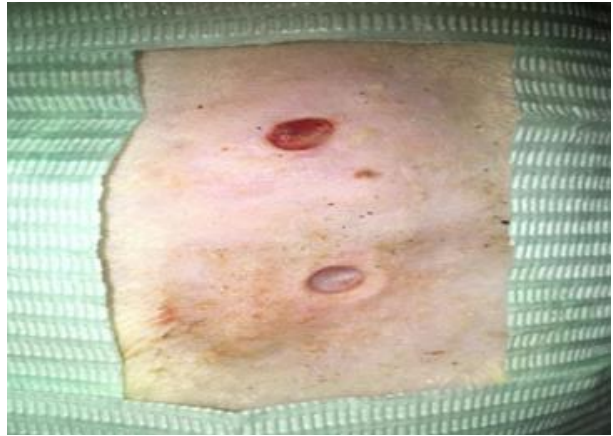

Figure (2): Wounds prepared

\section{Results}

\section{Histological findings}

\section{One day duration}

Histological examination of skin section of the control group wound shows scab tissue at surface, cut edge of the wound is noticed, Figure (3), numerous congested new blood vessels,inflammatory cells are noticed in dermis Figure (4).Histological examination after CZ application shows thickened epithelium, new hair follicles Figure (5), migration of keratinocytes at cut edge seen on surface Figure (6).

\section{Three days duration}

Histological examination of the control group wound shows necrotic tissue on wound surface scab extension is demarcated from new epithelial tissue proliferation,
Figure(6). Collagen fibers with fibroblasts, and developing hair follicles,Figure(7). After $\mathrm{CZ}$ application necrotic tissue on wound surface is shown, formation of new epithelial cells under the demarcation line which separates vital tissue from necrotic tissue ,hair follicles in dermis, Figure $(8,9)$.

\section{Seven days duration}

Histological examination of the control group shows new epithelium, remodeling collagen fibers, hair follicles,Figure $(10,11)$. Histological examination of wound site after CZ essential oil application shows complete epithelialization, hair follicles, fibroblasts associated with collagen fibers, numerous blood vessels with adjacent inflammatory cells ,Figure $(12,13)$. 


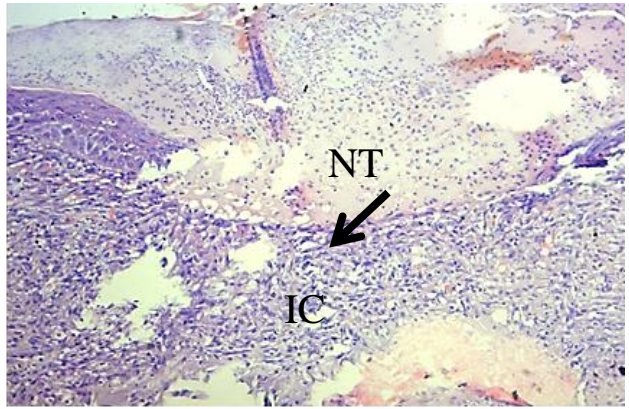

Figure (3): Photomicrograph of control side at day 1 shows necrotic tissue (NT) at surface (arrow) ,.H\&EX10

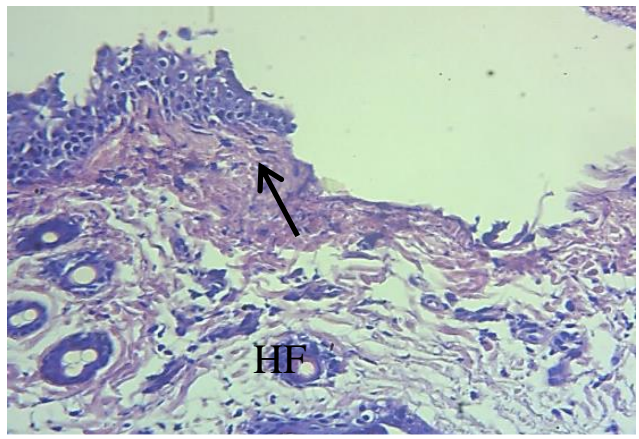

Figure (5): Photomicrograph of experimental side at day 1 shows thickened epithelium at cut edge (arrow), new hair follicles (HF). $\mathrm{H} \& \mathrm{EX} 20$

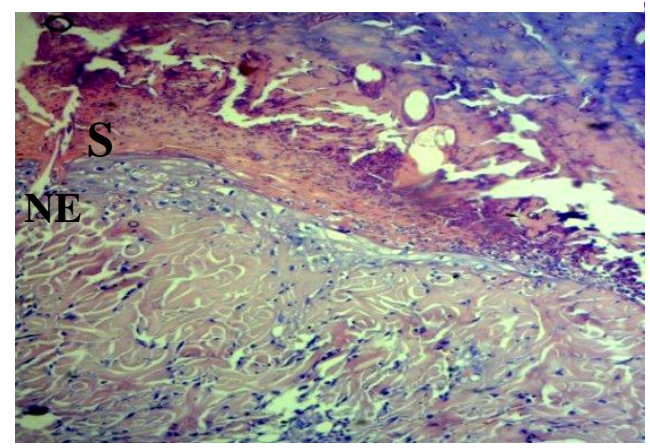

Figure (6): Photomicrograph of control side at day 3 shows scab(S) ,new epithelium(NE). H\&EX20

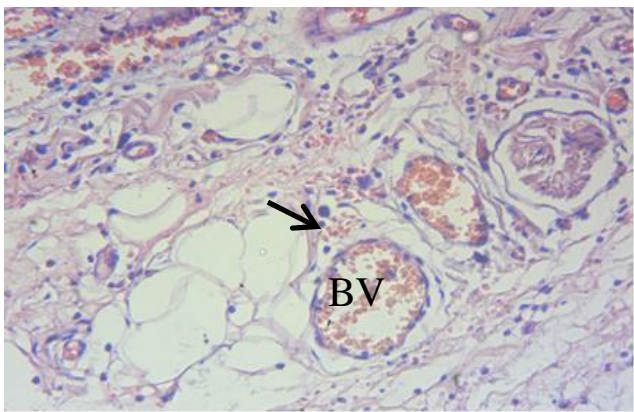

Figure (4): Photomicrograph of control side at day 1 shows inflammatory cells (IC)(arrow). Blood vessels (BV). H\&E X40.

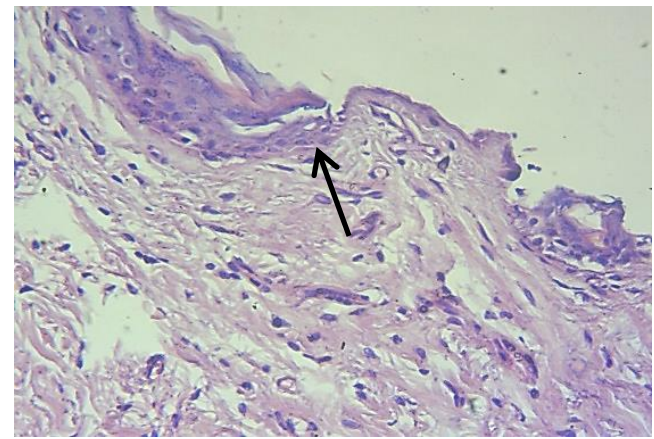

Figure (6): Photomicrograph of experimental side at day 1 shows migrating keratinocytes (arrow) H\&EX20

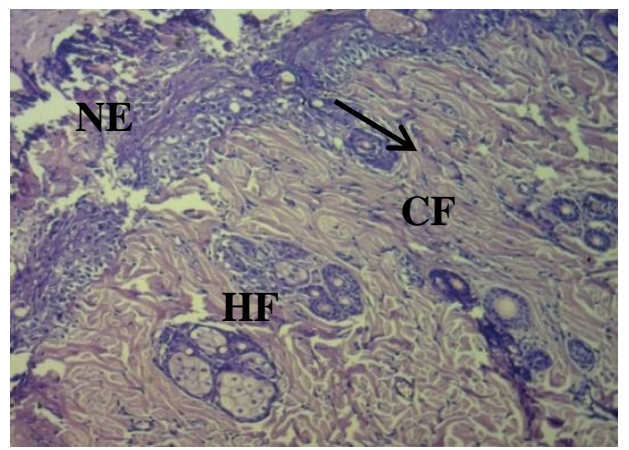

Figure (7): Photomicrograph of control side at day 3 shows new epithelial(NE). Collagen fibers (CF), fibroblast (arrow)and hair follicles(HF). H\&EX20 


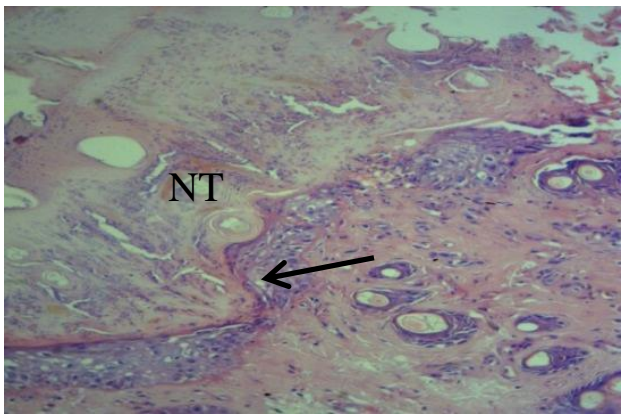

Figure (8): Photomicrograph of experimental side at day 3shows new epithelium (arrow). Necrotic tissue at the surface (NT). H\&EX10.

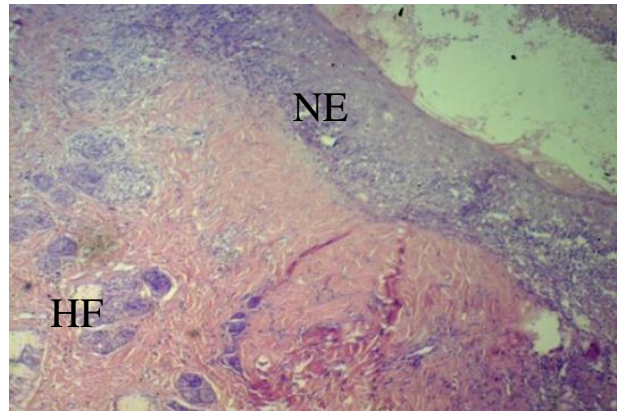

Figure (10): Photomicrograph of control side at day 7 shows new epithelial(NE), hair follicles(HF). H\&EX10.

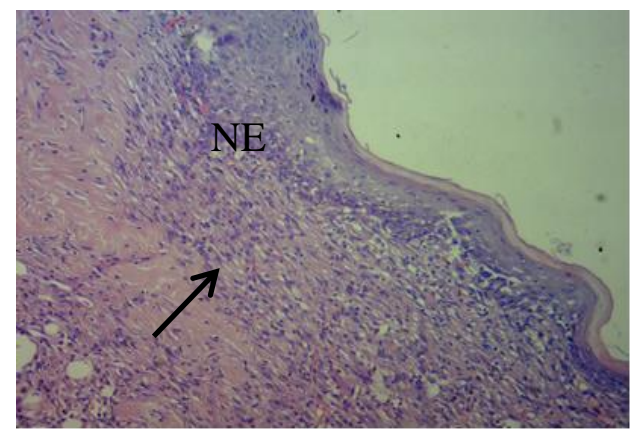

Figure (12): Photomicrograph of experimental side at day 7 shows new epithelial(NE). Fibroblasts with collagen fibers (arrow). H\&EX10

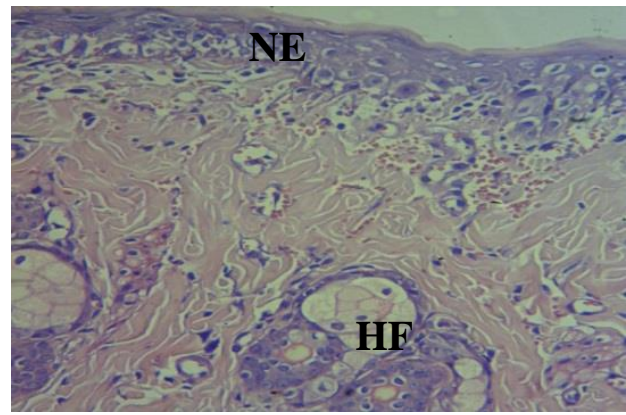

Figure (9): Photomicrograph of experimental side at day 3 shows new epithelium (NE).hair follicles(HF). H\&EX20.

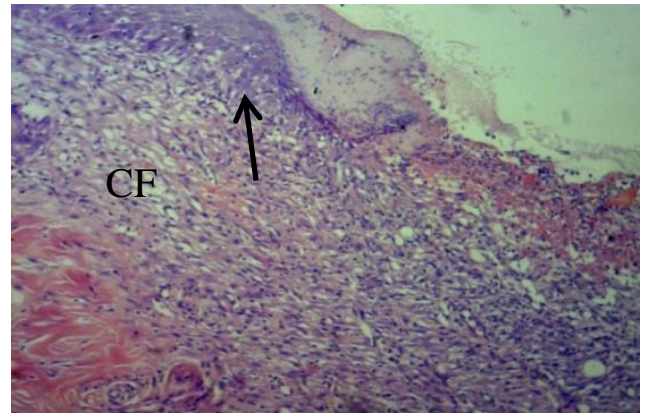

Figure (11): Photomicrograph of control side at day 7 shows epithelium(arrow), remodeling collagen fibers (CF). H\&E X20.

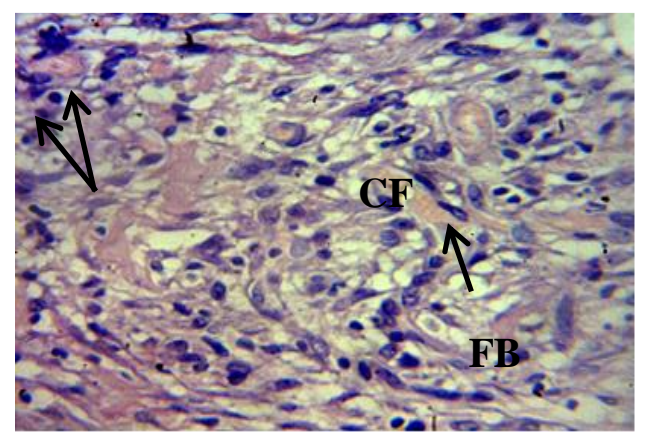

Figure (13): Photomicrograph of experimental side at day 7 shows collagen fibers (CF), fibroblast (FB). Inflammatory cell (arrow). H\&EX40 
Histological assessment of effect of Cinnamomum Zeylanicum Extract on Experimentally Induced

Cutaneous Wound Healing in Rats

\section{Estimation of wound contraction}

As illustrated in Table (1), the results of the present study shows that the measured mean values decreased with time. The lowest mean value was recorded for experimental group in day 7 and the highest mean value in day 1 for control group. Significant difference was recorded between control and experimental groups at day 3 whereas nonsignificant deference was recorded at day 1 and 7 in both groups.

\section{Inflammatory cell parameter}

The results revealed that mean values of inflammatory cell count decreased with time regarding experimental group. The highest mean value For Control group was recorded at day 3 and the lowest value was recorded at day 1 Figure (14).

\section{Epithelial thickness parameter}

Mean values of increased with time for experimental and control groups in different durations. The highest values of the mean recorded at day7in the experimental group and the lowest mean values at day lin the control group Figure (15).

\section{Blood vessel count}

The results revealed that the highest mean values of blood vessels number was counted for both groups at day 3. The lowest values for the mean was recorded for control group in day 1 and for experimental group was at day 7 Figure (16).

Table (1): Descriptive statistics of wound contraction in $(\mathrm{cm})$ for all groups in each healing period

\begin{tabular}{|c|c|c||c|c|c||c|c|c||}
\hline days & & $\mathbf{N}$ & Minimum & Maximum & Mean & SE & SD & P-value \\
\hline \hline Day1 & Control & 6 & 3.94 & 5.00 & 4.4883 & .16276 & 0.39867 & $0.217^{*}$ \\
\hline \hline & Exp. & 6 & 2.62 & 4.58 & 3.9083 & .28293 & 0.69303 & \\
\hline \hline Day3 & Control & 6 & 3.95 & 4.99 & 4.223 & .1655 & 0.4038 & $0.003^{* *}$ \\
\hline \hline & Exp. & 6 & 2.88 & 3.90 & 3.521 & 0.201 & 0.492 & \\
\hline \hline Day7 & Control & 6 & 1.84 & 8.40 & 4.1450 & .93319 & 2.28583 & $0.204^{*}$ \\
\hline \hline & Exp. & 6 & 1.98 & 2.97 & 2.6017 & .14750 & 0.36130 & \\
\hline $\begin{array}{l}* \mathrm{P}>0.05 \mathrm{NS} \\
* * \mathrm{P}<0.05 \mathrm{~S} \\
* * * \mathrm{p}<0.01 \mathrm{HS}\end{array}$ & & & & & & & \\
\end{tabular}




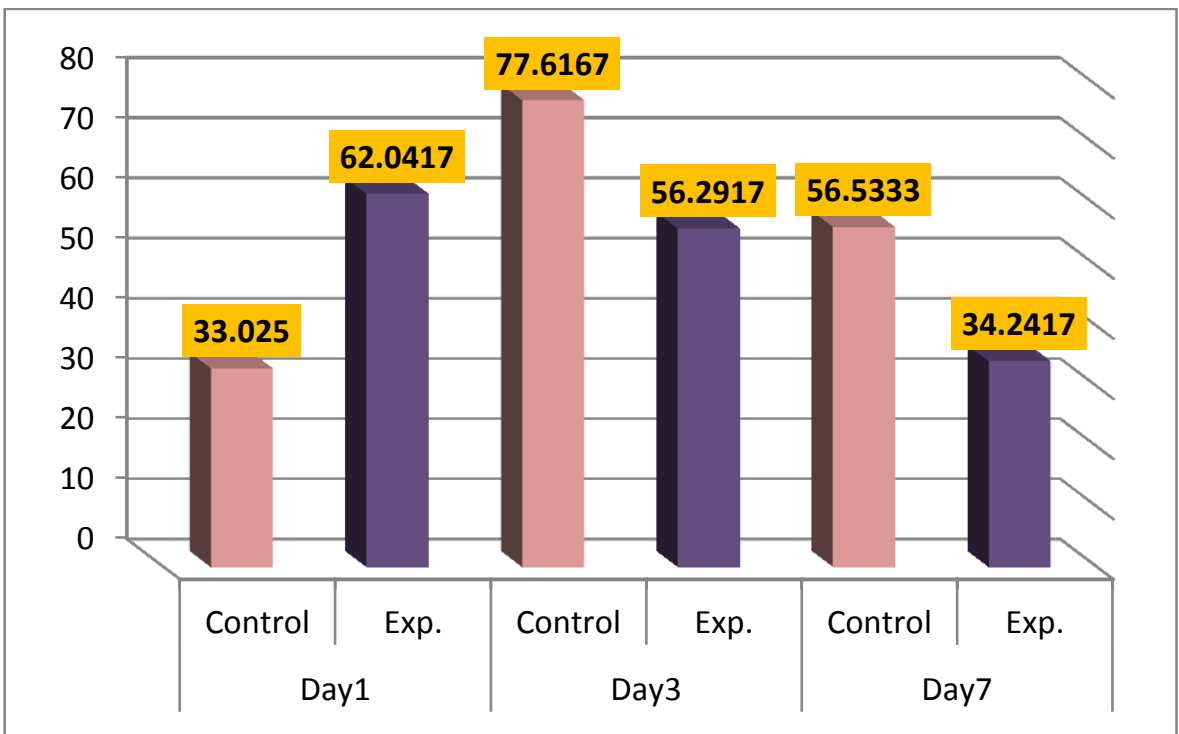

Figure (14): Comparison of the mean of inflammatory cells account of all groups for each healing period

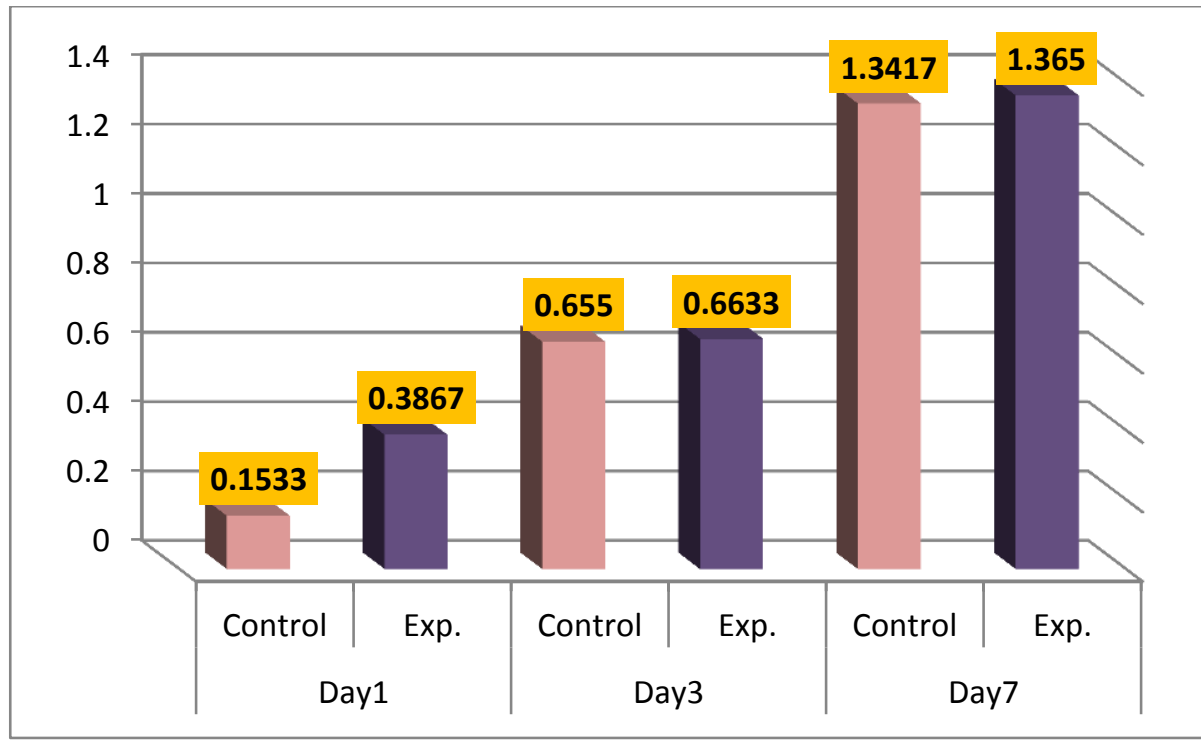

Figure (15): Comparison of the mean of epithelial thickness parameters of all groups at each healing period 
Histological assessment of effect of Cinnamomum Zeylanicum Extract on Experimentally Induced

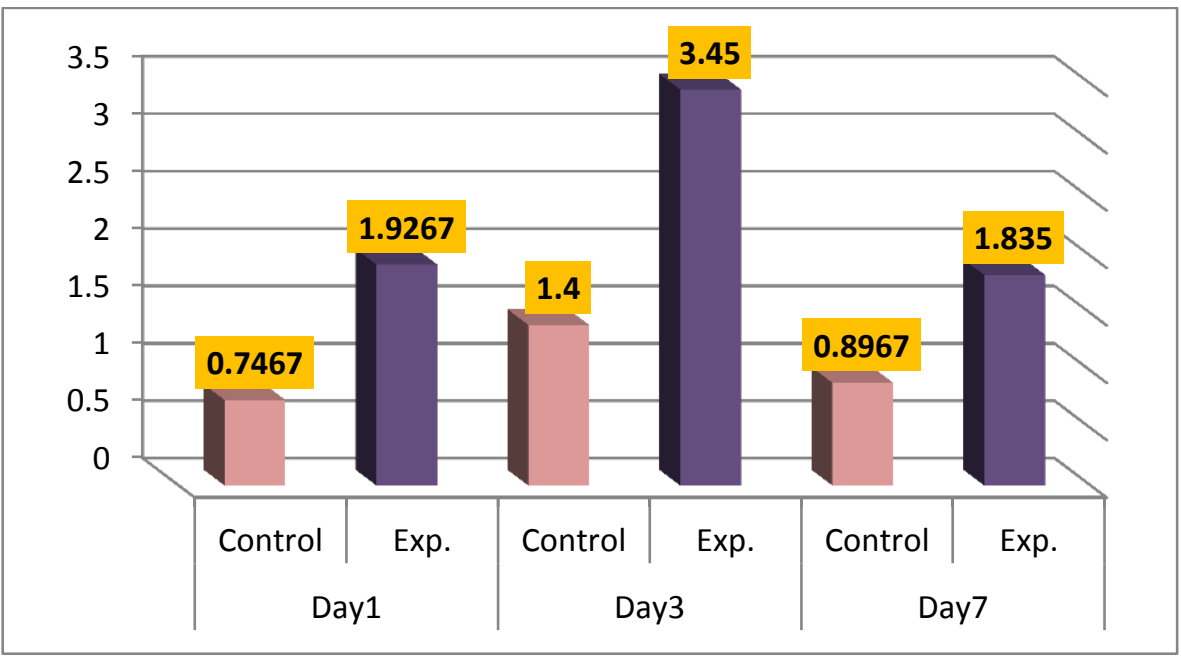

Figure (16): Comparison of the mean of blood vessels account of all groups at each healing period

\section{Discussion}

Wound is the loss of the cellular and anatomic continuity of the living tissue produced by electrical, chemical, physical or microbial stimuli to the tissue [10].

Healing process is a complex event that involves inflammation, reepithelization, blood vessels formation, granulation tissue deposition, and finally deposition of interstitial matrix, beside work of many cell types, such as fibroblasts , keratinocytes, endothelial cells, and inflammatory cells. [9,11]. Since long times, human used herbs to accelerate the wound-healing process [12]. Herbal treatment are presently used all around the world because of its effective and safe characteristics. Cinnamon Zeylanicum is a fuctional herb which has many therapeutic properties [13]. Since goal of the healing process is to promote fast wound closure and promote recovery of functional properties, hence the current study was designed to evaluate outcome of the essential oil of $\mathrm{CZ}$

on wound model in rats based on certain parameters: wound contraction, inflammatory cell count, blood vessels count, histologic features.

Rats supply an extraaodinary model for the healing process by permitting the standarization of the size, type, depth, and shape of the wound. Among rodents, rat skin is most structurally similar to human skin model [14] .Rats have mostly used in the observation of wound healing in the skin and the effectiveness of many treatment modules. This specific animal type have been selected for its, low cost, small size and availability [15].

\section{Wound contraction}

Wound contraction can be defined as the movement of the edges of the wound toward the center to close it. Contraction can precede the stage of maturation. The lateral migration and the proliferation of the keratinocytes occurs toward the area of damage [16].In this study mean values of wound contraction 
Histological assessment of effect of Cinnamomum Zeylanicum Extract on Experimentally Induced

Cutaneous Wound Healing in Rats

decreased with time in studied groups and lowest values were detected in experimental side as a compared to the control side in agreement with Farahpour and Habibi,2012 [3] who found that local $\mathrm{CZ}$ application reduces wound size, accelerates healing and can minimize the probable wound complications.

\section{Histological and histomorphometrical evaluation}

Microscopically, the orientation of collagen fibers, its variable pattern, different amount of mature and early collagen, and the absence or presence of inflammatory cells and the amount of granulation tissue was based on this histological parameters current healing state of the wound may be identified[17].

Results of this study showed a noticeable increase in the inflammatory cells numbers that penetrate into the wound area after $\mathrm{CZ}$ application at days 1 as compared to control group, where as at days 3 higher count was noticed for control group than other and this result in agreement with Vetala et al.,2013[18]who evaluated the effect of type-A procyanidine polyphenols extracted from Cinnamomum zeylanicum bark in rats and he stated that it has anti-arthritic and anti-inflammatory properties in animal models.

After 7days inflammatory cell mean values decreased in agreement with Kamil,2018[19] who studied effect of herbes (sage oil and myrrh)on rabbet skin wound healing process and indicated their an anti-inflammatory effect by decreasing the inflammatory cells count with time. on the first few days of the healing the process of re-epithelialization is essential for producing a barrier in between the inner and the outer environment toenable an undisturbed continuation of the developed repair processes [20].The present study showed that re-epithelialization for control and experimental groups recorded a highest mean value at day 7 . The re-epithelialization process progressesion could be attributed to increased proliferation in the epidermal cells with an increased angiogenesis. This agrees with Kumar ,2019[21] who used polyherbal carbopol-940 gels for excision wound model in rats and found that it accelerated epithelialization as compared to control group animals, also agreed with Muhammad ,2014 [22] who studied the outcome of curcumin topical application in skin wound healing in rabbits model and found that at day 7 ,treated group significantly differ from other groups which had highest mean value of epithelial thickness.

The phase of proliferative on wound healing process is very metabolic with raised nutrients demand and oxygen so the reproduction of blood vessels is highly important [23]. Neovascularization is an important event that takes place in the second stage of the healing process. Restriction of the flow of the blood to the wound area caused disruption in the repair process, involving decline anabolic activity, weakened cell defenses and local immune, protein malnutrition, shortage of growth factors and oxidative stress. Angiogenesis is important determinant in the repair process, which enables nutrient and oxygen arrival to 
Histological assessment of effect of Cinnamomum Zeylanicum Extract on Experimentally Induced

Cutaneous Wound Healing in Rats

the wound site and the reepithelialization and facilitate the collagen synthesis [24].

Results obtained in this study showed that highest mean values of blood vessels count detected at day 3 in experimental groups the lowest values were at day 7 in control group in agreement with Kamil,2108[19] who reported that the mean values of blood vessels recorded a highest count after $\mathrm{CZ}$ application at day 3, and at day 7 for the other group. The lowest values for the mean recorded for both groups after 24 hours.

\section{Conclusions}

The present study concluded that using local CZ essential oil is effective in accelerating cutaneous wound healing.

\section{References}

[1] Shaw TJ, Martin P. Wound repair at a glance. J Cell Sci. 2009: 122:3209-3213.

[2] Kane D. Chronic wound healing and chronic wound management.In: Krasner D, Rodeheaver GT, Sibbald RG (eds). Chronic Wound Care:A Clinical Source Book for Healthcare Professionals, 4th ed. Wayne,PA: Health Management Publications; 2006:1124.

[3]Farahpour MR., HabibiI M. Evaluation of the wound healing activity of an ethanolic extract of Ceylon cinnamon in mice. Veterinarni Medicina.2012:57 (1): 53-57.

[4]Lee SH, Lee SY, Son DJ, Lee H, Yoo HS, Song S, OH KW, Han DC, Kwon BM, Hong JT. Inhibitory effect of 20hydroxycinnamaldehyde on nitric oxide production through inhibition of NF[kappa]B activation in RAW 264.7 cells. Biochem. Pharmacol. 2005:69:791-799.
[5]Lee SH.,Gao J.R.,Yoon K.S.,Mumcuoglu K.Y. Tablin D.sodium channel mutation associated with knockdown resistance in the human head louse pediculus capitus (De Geer).pestic.biochem.physiol. 2003:75:7991.

[6]Singh G, Maurya S, Delampasona MP. A comparison of chemical, antioxidant and antimicrobial studies of cinnamon leaf and bark volatile oils, oleoresins and their constituents. Food Chem. Toxicol. 2007:45:1650-1661.

[7]Matan, N., Rimkeeree, H. Mawson, A.J., Chompreeda,P., Haruthaithanasan, V. and Parker, M..Antimicrobial. activity of cinnamon and clove oilsunder modified atmosphere conditions. International Journal of Food Microbiology .2006:107(2): 180185.

[8]Moreira Cf., Vieira PC.,Silva MF. Skin Wound Healing Model - Excisional Wounding and Assessment of Lesion Area. bio-protocol.

2015:10.217.

[9]Liu H., Lin S.,Xiao D.,GU Y.,Guo S. Evaluation of the wound healing potential of Resina Draconis (dracaena cochinchinesis) in animal model. Evidence-Based Complementory and Alternative Medicine.2013: 1-10.

[10]Dons T., Sooairaj S. Evaluation of wound healing effect of herbal lotion in albino rats and its antibacterial activities. Clinical Phytoscience .2018: 4:6.

[11]Heng MC. Wound healing in adult skin: aiming for perfect regeneration. Int $J$ Dermatol. 2011: 50(9):1058-1066. 
Histological assessment of effect of Cinnamomum Zeylanicum Extract on Experimentally Induced

Cutaneous Wound Healing in Rats

[12]Liu H., Lin S., Xiao D., Zheng X., GU Y., Guo S. Evaluation of the Wound Healing Potential of Resina Draconis (Dracaena cochinchinensis) in Animal Models. Evidence-Based Complementary and Alternative Medicine. 2013:vol:1-10.

[13]Fronza M., Heinzmann B., Hamburger M., Laufer S., Merfort I. Determination of the wound healing effect of Calendula extracts using the scratch assay with $3 \mathrm{~T} 3$ fibroblasts,

Journal ofEthnopharmacology.2009: $126(3): 463$ 467.

[14]Štefan F, Zita F, Iveta P, Juraj K. Effect of Cinnamomum zeylanicum Essential Oil on Antioxidative Status in Broiler Chickens. Acta. Vet. Brno. 2009:78:411-417.

[15]Dorsett-Martin WA., Wysocki AB. Humana Press Inc. Models of Skin Wound Healing. Rat Sourcebook of Models for Biomedical Research. 2008:Ch65,p:63-638. [16]Marza S., Magyari K., Bogdan S., Moldovan M. Skin wound regeneration with bioactive glass-gold nanoparticles ointment. Schoarly research journal. 2019:10.1088/1748-605X/aafd7d.

[17] Sabiston, C., Townsend and Courtney, M..Sabiston textbook of surgery. The biological basis of mdern surgical practi. Philadelphia, PA, Elsevier Saunders 2012:19:163-165.

[18]Sultana J., Molla MR., Kmal M., Shahidulah M., Begum F., Abul Basha MD. Histological differences in wound healing in Maxillofacial region in patients with or without risk factors. Bangladesh $\mathrm{J}$ Pathol 2009:24 (1) : 3 .
[19]Vetala S., Bodhankara SL. ,Mohanb V., Thakurdesaib PA. Anti-inflammatory and anti-arthritic activity of type-A procyanidine polyphenols from bark of Cinnamomum zeylanicum in rats. Food Science and Human Wellness. 2013:22(2) : 59-67.

[20]Kamil NB. Effect of local exogenous application of myrrh and/or sage oil in incisional wound healing. Msc thesis,Baghdad university. 2018:ch3, p:5769.

[21]Sabol F., Dancakova L., Gal P., Vasilenko T., Novotny M., Smetana K., Lenhardt L. Immunohistological changes in skin wounds during the early periods of healing in a rat model. Veterinarni Medicina. 2012:57, (2): 77-82.

[22]Kumar S., Choudhury PK., Srivastava R., Sharma M. Antimicrobial, antiinflammatory and wound healing activity of polyherbal formulation. Biomedicine \& Phamacotherapy. 2019: 111:555-567.

[23] Muhammad NH.(2014). Evaluation the Effect of Topical Application of Curcumin Powder and Essential Oil on Skin Wound Healing in Rabbits.Msc thesis,Baghdad university.ch3,p:65-72.

[24]Lali FV., Metcalfe AD. The role of angiogenesis in wound healing, scarring and tissue regeneration. PMFA News. 2014:VOL2(1).

[25] Gurtner, GC. Werner, S. Barrandon, Y. and Longaker, MT. Wound repair and regeneration. Nature.2008:453 (7193),314321. 